\title{
Intergroup Contact Attitudes Across Peer Networks in School: Selection, Influence, and Implications for Cross-Group Friendships
}

\author{
Deborah Rivas-Drake and Muniba Saleem \\ University of Michigan
}

\author{
David R. Schaefer \\ University of California, Irvine
}

\author{
Michael Medina and Robert Jagers \\ University of Michigan
}

\begin{abstract}
This study offers new insights into the power of peer networks for shaping intergroup relations in a diverse school. Data were drawn from a longitudinal study of sixth-eighth graders $\left(N=524 ; M_{\text {ageT1 }}=11.87 ; 48 \%\right.$ girls; 9\% Asian American/Pacific Islander, 28\% African American, 13\% Latino, 1\% Native American, 31\% White, $5 \%$ Other, and $11 \%$ Multiracial) in the Midwestern United States. Students with more positive intergroup contact attitudes (ICA) were most likely to be friends with similarly minded students. Students with more positive ICA were less likely to select friends of the same race/ethnicity than those with less positive ICA. Finally, students' ICA became more similar to their friends' ICA over time. Results implicate school-level norms and contagion in students' ICA.
\end{abstract}

The increasing ethnic diversity of the U.S. youth population portends the heightened potential for youth to engage with individuals of ethnic/racial backgrounds different from their own. However, the fact of diversity itself is insufficient for individuals to benefit from growing up in a multicultural society (Thijs \& Verkuyten, 2014). Even in diverse contexts that provide opportunity for intergroup interaction, adolescents vary in the extent to which they are interested in and capable of actually engaging in such interactions (Graham, Munniksma, \& Juvonen, 2014; Moody, 2001; Ramiah, Schmid, Hewstone, \& Floe, 2015). This suggests there are important individual differences in the extent to which youth benefit from exposure to diverse peers and engage with such opportunities in productive ways (e.g., by forming cross-group friendships; Graham et al., 2014; Tropp, O'Brien, \& Migacheva, 2014). Greater understanding of what promotes engagement in and sustenance of cross-group friendships, in particular, is sorely needed, as these tend to decline with age (e.g., Aboud, Mendelson, \& Purdy, 2003; see also Turner \& Cameron, 2016).

More research is needed on processes that may facilitate youths' ability to interact with diverse

The authors gratefully acknowledge the Origins Program and the participating school for their partnership in this research.

Correspondence concerning this article should be addressed to Deborah Rivas-Drake, University of Michigan, 530 Church Street, Ann Arbor, MI 48109. Electronic mail may be sent to drivas@umich.edu. peers in positive and effectual ways. The ability to engage effectively across ethnic/racial groups has implications for other important social and developmental outcomes (e.g., Bagci, Rutland, Kumashiro, Smith, \& Blumberg, 2014; Fletcher, Rollins, \& Nickerson, 2004; Lease \& Blake, 2005) as well as later educational experiences (e.g., college), the workforce, and positive intergroup relations in broader society (e.g., Gieling, Thijs, \& Verkuyten, 2014; Gurin, Dey, Hurtado, \& Gurin, 2002; Jayakumar, 2008; Kawabata \& Crick, 2008, 2011, 2015; Pettigrew \& Tropp, 2008; Reimer et al., 2017; Saleem, Yang, \& Ramasubramanian, 2016). Indeed, this capacity is part and parcel of youths' social awareness and relationship skills, which are two of the five core social-emotional competencies promoted by the Collaborative for Academic, Social, and Emotional Learning (i.e., CASEL 5; Weissberg, Durlak, Domitrovich, \& Gullotta, 2015).

Theory and extensive research suggest that conditions that reduce prejudice in intergroup interactions (e.g., Allport, 1954; Pettigrew \& Tropp, 2012; Tropp \& Pettigrew, 2005) support youths' ability to adapt to heterogeneous environments and endorse a positive orientation toward intergroup relations (e.g., appreciating and valuing diversity; Tropp \&

(C) 2018 Society for Research in Child Development All rights reserved. 0009-3920/2019/9006-0006 DOI: $10.1111 /$ cdev.13061 
Bianchi, 2006; Verkuyten, 2007). What is less clear is the extent to which peer influence processes play a role in youths' interest in and valuing of intergroup contact experiences. For example, are youth likely to form friendships with students who share their attitudes toward intergroup contact? In addition, to what extent do friends influence one another's intergroup contact attitudes (ICA)? These were the major questions investigated in this study.

\section{Theoretical Framework}

This study uses two distinct but complementary frameworks. First, we draw from intergroup contact theory (Allport, 1954; Pettigrew \& Tropp, 2012), which posits that youth will be more disposed toward intergroup contact when there are supportive norms (i.e., authority sanction) in the setting (see Tropp et al., 2016). Although the school investigated in this study is not implementing specific prejudice reduction approaches, it is engaged in practices that are meant to promote inclusiveness. Specifically, the administration has been in the process of implementing a school-wide social-emotional learning program that aims to support a positive and normative view of the school as one inclusive community, which is reinforced by teacher practices and peers' mutual regulation of one another. The program's literature notes that it was designed with a philosophy about inclusion and equity; however, it - like many other SEL programs -adopts a colorblind approach in that none of the activities or practices explicitly engage issues of race, ethnicity, or other social identities with students (Jagers, 2016).

Yet, school conditions that encourage inclusiveness may not be sufficient, as intra-school dynamics among peers may also play a role in youths' dispositions toward engaging with peers from diverse groups. This is because peers provide useful social information to one another throughout adolescence (Galván, Spatzier, \& Juvonen, 2011), which has broad implications for how they engage with others in schools. For example, Tropp et al. (2016) found that adolescents' perceptions of their peers' norms toward intergroup contact were positively related with their own intergroup attitudes, including their feelings of comfort and interest in interethnic friendships. These peer dynamics may be further complicated by broader, potentially distinct social norms of their shared context, like their school or classroom. Among adolescents, exposure and adherence to such norms have been found to be associated with a variety of social behaviors, including aggressiveness, academic achievement, and prosocial behavior (Dijkstra \& Gest, 2015; Laninga-Wijnen et al., 2017).

To conceptualize such peer dynamics, we employ a second theoretical framework by Brown, Bakken, Ameringer, and Mahon (2008). According to this framework, the extent to which peers influence each other on given behaviors is contingent on the target's openness to influence (i.e., own intergroup contact dispositions), the salience and nature of the peer influencers (i.e., friendship context), and the extent to which the target has the capacity and opportunity to conform to or enact particular behaviors (e.g., ethnically heterogeneous setting). In this study, we posit that youth with particular ICA will seek others who share their views because they will be comfortable around others who share their values around diversity. We reasoned that drawing on both frameworks allows us to better explicate how youth construct norms around intergroup contact in ethnically heterogeneous settings. In particular, we are able to better capture how peers may serve as socializing agents in regard to intergroup relations within an ethnically heterogeneous setting that provides supportive conditions (i.e., authority sanction) for contact.

\section{Peers and Intergroup Attitudes Among Adolescents}

Changes in peer structures and influence emerge in adolescence. Peer processes, such as homophily (i.e., associating with similar others), are important for a wide range of issues during this period of life (e.g., McPherson, Smith-Lovin, \& Cook, 2001; Veenstra, Dijkstra, Steglich, \& Van Zalk, 2013). Adolescents' ICA (e.g., valuing friendships with diverse others) are likely no exception to the more general pattern of homophily, as empirical research shows that peer contexts influence youths' understanding of ethnic/racial norms (e.g., Ramiah et al., 2015; Tropp et al., 2016). This observation has been made in numerous ethnographic accounts that find that adolescents' understanding of ethnic/racial norms in heterogeneous schools are constructed and reinforced among peers (e.g., Lee, 1996; McLeod, 1995; Pollock, 2004; Rosenbloom \& Way, 2004; Valenzuela, 1999). Thus, it appears that there is an important interplay between peer interactions and youths' attitudes toward ethnic and racial features of their social experiences, especially in heterogeneous settings.

Experimental studies find that direct, vicarious, and extended intergroup contact opportunities at school are linked to individuals' assessments of 
racially relevant situations. For instance, McGlothlin and Killen (2010) argued and found that children's social experience (i.e., having intergroup contact at a racially heterogeneous school) was associated with lower ingroup bias in ratings of a hypothetical transgressor. In addition, White and Black students attending heterogeneous schools reported similar likelihoods in the potential for friendship between a Black transgressor and White victim and a White transgressor and Black victim. Wright, Aron, McLaughlin-Volpe, and Ropp (1997) extended contact hypothesis argues that the benefits associated with cross-group friendship might also stem from vicarious experiences of friendship, that is, the knowledge that ingroup members have outgroup friends. If an outgroup member is observed being friendly and positive to an ingroup member (e.g., has a friendship), individuals' expectations about intergroup interactions may be more positive. Moreover, seeing an ingroup member being friends with an outgroup member suggests that they are tolerant of the outgroup, which may influence the attitudes of other ingroup members by establishing the norm for the appropriate behavior toward outgroup members. A series of cross-sectional and experimental studies have demonstrated that people who know ingroup members with outgroup friends show reduced intergroup bias (Cameron, Rutland, Brown, \& Douch, 2006; Crystal, Killen, \& Ruck, 2008; Turner, Hewstone, \& Voci, 2007; Turner, Hewstone, Voci, \& Vonofakou, 2008; Wright et al., 1997; for a review, see Turner, Hewstone, Voci, Paolini, \& Christ, 2007).

Peer attitudes and norms related to intergroup contact are also associated with participants' own interest in intergroup contact (e.g., Carlson, Wilson, \& Hargrave, 2003; Kiesner, Maass, Cadinu, \& Vallese, 2003; Ramiah et al., 2015; Tropp et al., 2016; Turner et al., 2008). For example, in a study of an ethnically mixed (British and Southeast Asian) high school in the United Kingdom, Ramiah et al. (2015) found that both British and Southeast Asian students attributed both the ingroup's and outgroup's lack of intergroup interaction to a lack of interest. Indeed, peer conformity is known to peak during early adolescence (e.g., Brown, 1990), further highlighting the importance of peer attitudes and norms related to intergroup contact. Individuals who hold positive perceptions of ingroup norms toward the outgroup, and who realize that behaving positively toward the outgroup will not be negatively sanctioned by others, may be especially likely to seek intergroup contact themselves. For example, Turner et al. (2008) found that adolescents' perceived peer attitudes toward outgroups were significantly and positively associated with participants' own outgroup attitudes. Tropp et al. (2016) found that adolescents who perceived that their same-ethnic friends valued and approved of having school friends from the other ethnic group were themselves more comfortable and interested in crossgroup interactions. Similarly, among a sample of Hispanic early adolescents, perceptions of close friends' comfort level with cross-race social interaction predicted more favorable other-group orientation, above and beyond school diversity and direct cross-group friendships (Carlson et al., 2003). Finally, British and Southeast Asian students' perceptions of ingroup norms for intergroup contact (i.e., encouragement by friends and family to have such contact) at an earlier point in time predicted the likelihood that they chose to sit with outgroup students in a hypothetical scenario presented 6 months later (Ramiah et al., 2015).

A limitation of extant work is that peer attitudes and norms regarding intergroup contact are often assessed using explicit reports of the participant's perceptions of peer norms and thus are subject to participants' own biases, such as the tendency to believe that others are more similar to oneself than may be the case (Thijs \& Verkuyten, 2014). In contrast, analysis of adolescents' friendship networks provides an important complement to prior work on this topic by examining peer influence through an implicit measure less susceptible to participants' own biases. As we know from research on peer networks and myriad facets of adolescent experiences, unstated peer norms (e.g., homophily that manifests via selection and influence processes) play an important but not necessarily explicit role in youths' outcomes (e.g., mental health, social behavior, substance use; Osgood et al., 2013; Schaefer, Kornienko, \& Fox, 2011; Sijtsema et al., 2010). As a peer network approach does not rely on youths' reports of their friends' intergroup attitudes, results accordingly tell us about tacit agreement and implicit socialization among peers with regard to the value of intergroup contact. Applying this methodological and analytic approach, this study examined the extent to which early adolescents' ICA were influenced by those of their proximal peers and friends in an ethnically diverse school.

To our knowledge, no studies have examined the relation between ICA and friendship ties among adolescents using a method that can parse the role of selection from socialization in ICA among friends. However, it follows from the logic of intergroup contact theory that feeling valued and 
accepted by outgroups can promote a positive disposition toward contact in diverse settings. For instance, Tropp and Bianchi (2006) found that, among ethnic minority college students aged 17-22, perceived interest by the outgroup (majority students) in having contact was associated with their perception that the outgroup valued diversity, and this in turn predicted students' own interest in having intergroup contact. That is, students who are otherwise stigmatized but are made to feel safe and comfortable in heterogeneous situations may be more motivated to engage with outgroup members. One reason for this may be that youth seek out peers who have similar dispositions toward intergroup contact, but another is that youth are sensitive to the intergroup attitudes of peers and their own attitudes change over time as a result.

As we consider youths' navigation of peers' intergroup attitudes, we also must account for how adolescents' own understandings of ethnicity and race may inform their interactions in ethnically diverse settings (e.g., Phinney, Ferguson, \& Tate, 1997; Verkuyten, 2005). Specifically, youth vary in the meaning ascribed to the role of ethnicity/race in their lives (Sellers, Rowley, Chavous, Shelton, \& Smith, 1997; Sellers, Smith, Shelton, Rowley, \& Chavous, 1998), and an extensive literature indicates that such beliefs are related to a number of important adjustment outcomes (Rivas-Drake et al., 2014). One such aspect that is particularly pertinent to youths' interactions in heterogeneous spaces is their sense of public regard, which refers to their perceptions of others' views of their ethnic/racial group (Sellers et al., 1998). Among dimensions of ethnicracial identity, public regard's focus on youths' awareness of external racial attitudes and beliefs is particularly relevant for consideration in this study.

\section{This Study}

Drawing from the aforementioned literature, we sought to examine three distinct questions related to peer influences and youths' ICA among adolescents in an ethnically and racially heterogeneous middle school. First, we examined the extent to which ICA were similar within the friendship networks of sixth, seventh, and eighth grade students. We have chosen to focus on early adolescence in an effort to broaden the literature examining the intersection of intergroup contact and friendship; while early adolescence is a time of increasing friendship salience and social development (Brechwald \& Prinstein, 2011; Umaña-Taylor et al., 2014), much of the extant work in this area has focused on older adolescents.
Our first hypothesis pertains to the role of selection processes. Given the extensive literature underscoring homophily along numerous facets of adolescent social experience, we expected students to form friendships with peers who have similar levels of ICA. In our primary analyses, we considered ethnic/racial category, gender, and immigrant generation as potentially important covariates of homophily (cf. McPherson et al., 2001). We also considered whether students participated in the same advisory (homeroom) for two reasons. First, advisory in this school was a key setting for the implementation of the social-emotional learning program discussed earlier; this is where students practiced perspective-taking and other competencies related to the central question of this study. Second, it is well-established that, due to tracking practices in U.S. schools, students' courses are typically scheduled such that they engage with a cohort of peers. Sharing a setting such as an advisory meant that students were also likely to see each other in other courses during the day, which might promote homophily due to propinquity (access); this makes it an important factor to take into account in this study (Schaefer, Simpkins, \& Ettekal, 2018). Lastly, we considered adolescents' public regard attitudes as a possible covariate of note, as youth may seek out peers who have a similar sense of others' acceptance and valuing of their ethnic/racial group.

Second, we explored the extent to which youth influence the ICA of their friends. For our second hypothesis, we predicted that, given extant literature on the role of friends on youths' social attitudes and beliefs, ICA among sixth through eighth grade students would become more similar to their friends' ICA over time. Among adolescents, peers and friends serve as salient social reference groups (Brown \& Larson, 2009) and sources of information regarding ingroup norms and expectations (Aboud, 2005). Such influence has been found to relate to numerous interpersonal and psychological outcomes in school settings, including individuals' sense of social belongingness (Lerner \& Steinberg, 2009), ethnic/racial identity beliefs (Rivas-Drake, Umaña-Taylor, Schaefer, \& Medina, 2017), and attitudes about other groups (Wright et al., 1997). In the case of this study, we took into account any confound between youths' intergroup attitudes and public regard perceptions, by modeling peer socialization influence on each (cf. Santos, Kornienko, \& Rivas-Drake, 2017). More generally, we expected the school context to be particularly encouraging of positive peer influence regarding intergroup context (i.e., authority sanction); the 
school's social-emotional learning program intentionally encourages the development of social competencies in a collaborative space (daily advisory periods) under the guidance of supportive authority figures. As the program is a universal, school-wide endeavor, authority sanction for positive intergroup relations may be manifest in arguably all sectors of the school.

Third, we considered the relationship between each of the previous aims in concert: ingroup/outgroup membership, friend selection, and ICA. For our third hypothesis, we predicted that as youths' friends feel increasingly valued and accepted by outgroup members, the willingness to engage in cross-group interactions would increase both for sixth through eighth grade students and their friends (e.g., Tropp \& Bianchi, 2006); conversely, if youths' friends felt more devalued over time, they and their friends' willingness to engage across groups would decrease accordingly. In other words, we explored the role of ICA as a moderator, influencing the extent to which youths' report outgroup friendships. We predicted that youth with more positive ICA will be more likely to report outgroup friendships than youth with less positive ICA. Given the ethnically and racially heterogeneous student population available at the study school, we also explored this prediction across groups while accounting for immigrant heritage; thus, we explored the extent to which ICA may differentially influence diverse youth populations.

\section{Method \\ Participants}

Data were drawn from a larger study of socialemotional climate in an urban Midwest U.S. middle school. To be included in the analysis, students must have been present and have a valid score for ICA during at least one of the three data collection waves. Thirty-three of the students surveyed were excluded because they did not have valid ICA and public regard data for at least one wave $(94 \%$ of students were retained). The middle school consists of sixth, seventh, and eighth grade students, and the analytical sample includes three grade cohorts: Cohort 1 is seventh grade students at Time 1 $(n=181)$; Cohort 2 is sixth grade students at Time $1(n=191)$; Cohort 3 is students who entered the study at Time 2 as sixth graders (i.e., fifth graders during Time $1 ; n=152$ ). Times 1,2 , and 3 of the study took place during the spring of 2014, fall of 2014, and spring of 2015, respectively, and data were collected from students attending the school at each point of data collection. Students were on average 12 years old $\left(M_{\text {ageT1 }}=11.87, S D=.72\right.$; $\left.M_{\text {ageT3 }}=12.41, S D=.95\right)$. The sample comprised Asian American and Pacific Islander (9\%), African American (28\%), Latino (13\%), Native American $(1 \%)$, White $(31 \%)$, Other $(5 \%)$, and Multiracial (11\%) students. This ethnic-racial distribution is representative of the school population, with each sample group proportion within $2 \%$ of its proportion within the whole school at Time 1. At Time 1, 19\% of students reported having an immigrant mother, and at Time 2, about $28 \%$ did so. According to publicly available aggregated school data, approximately $52 \%$ of students were eligible for free or reduced-price lunch. Rates of missing data across waves were quite low (see Table 2). Although we do not have recruitment rates for Time 1, we do know that at Time 2 (i.e., 2014-2015 school year), $92 \%$ of students attending the school participated in the survey. Tests comparing students present at all eligible waves to those missing one or more waves revealed no significant differences across study variables. The only difference we found was that sixth and seventh graders were more likely to be missing a wave of data than fifth graders (i.e., those who entered the study as sixth graders at T2); this is not surprising since the latter had one less wave of data collection.

\section{Procedure}

Student surveys were self-administered during homeroom; students were assured of the confidentiality of their responses (i.e., with the statement that "your individual answers will be private and will never be shared with anyone at this school" on the survey cover sheet). Surveys were de-identified such that all names were removed and replaced with ID codes by an external consultant who is not affiliated with the research team or with the school. After this de-identification process, the surveys were given to the university team for analysis. The project was determined to be Exempt by the University of Michigan Institutional Review Board.

\section{Measures}

\section{Intergroup Contact Attitudes}

Phinney's (1992) six-item Other Group Orientation scale (T1-T3 $\alpha$ range $=.76-.80$ ) was used to assess students' personal interest in and valuing of intergroup contact-precisely what the scale was 
designed to assess. The items are as follows: "I like meeting and getting to know people from ethnic groups other than my own;" "I enjoy being around people from ethnic groups other than my own;" "I sometimes feel it would be better if different ethnic groups didn't try to mix together" (reverse-coded); "I often spend time with people from ethnic groups other than my own;" "I don't try to become friends with people from other ethnic groups" (reversecoded); and "I am involved in activities with people from other ethnic groups" $(1=$ strongly disagree, $5=$ strongly agree). All items were coded such that higher values on this scale indicate more positive ICA.

\section{Peer Networks}

To identify influential peers, youth were asked to list their closest friends, or who they "hang around with and talk to the most" in their grade, which is a typical network name generation approach among youth in this age group (Ryan, 2001); this definition also permits us to examine the kind of friendship identified by Davies, Tropp, Aron, Pettigrew, and Wright (2011) as most consistently related to intergroup attitudes. Students could list "as many or as few" names; thus, there were no limits on nominations.

\section{Covariates}

Ethnic/racial category, gender, and mother's immigrant generation were included as covariates to account for demographic attributes that are likely to underlie homophily among friends (McPherson et al., 2001; Moody, 2001); their inclusion diminishes the likelihood of spurious findings. All were self-reported by youth in a demographic portion of the survey. Students were asked to indicate which ethnic/racial labels they identified with in the demographic portion of the questionnaire (multiple responses permitted) as well as in an open-ended question just before items pertaining to public regard. From these responses, ethnic/racial categories were identified that corresponded to six categories available in the U.S. Office of Civil Rights 2011-2012 report of school demographics (http:// ocrdata.ed.gov/) and a seventh category ("Other") to accurately reflect students' self-identification. Ethnic/racial categories were dummy coded 1 for a given group (e.g., Latino, African American, Asian American and Pacific Islander, Other, Multiracial, or White) and 0 for all others. Native American students were collapsed with the "Other" group due to the small number of students; thus, a total of five dummy codes were used for ethnic/racial category. Gender and mother's immigrant status were reported by students. Gender was coded 1 for male and 0 for female. Mother's immigrant generation was coded 1 for immigrant and 0 for U.S. born. Grade in school was coded 1 for a given grade (i.e., sixth, seventh, or eighth) and 0 for all else, resulting in three dummy codes (and in the analyses, one is excluded as the reference group).

In addition to the aforementioned demographic covariates, students' public regard perceptions were included (Scottham, Sellers, \& Nguyên, 2008), which was assessed with three items in which youth reported their views of others' regard for their ethnic group (e.g., "People think that people of my ethnicity are as good as people from other ethnicities;" 1 = strongly disagree, 5 = strongly agree; (T1-T3 $\alpha$ range $=.69-.82$ ). Higher values indicate more positive public regard. Finally, an indicator of which advisory (homeroom) period the student was in during Year 2 was used to account for the likelihood that students who were in the same advisory would be more likely to be friends given (a) proximity and that (b) a significant component of the social-emotional program being implemented in the school was focused on having students develop meaningful relationships during advisory. The ethnic composition of homeroom periods largely mirrored the overall school. Using the index of qualitative variation (IQV), which represents the probability that any two randomly chosen students will be of a different race (Moody, 2001), classroom race/ethnic heterogeneity ranged from .66 to .77 with a mean of .72 $(S D=.03)$.

\section{Analytic Approach}

We used a stochastic actor-oriented model, or SAOM (Snijders, Van de Bunt, \& Steglich, 2010), to model the co-evolution of the friendship network, ICA, and public regard. The SAOM is a dynamic network model that helps understand friendship change over time while also allowing for endogenous change in individual attributes. The SAOM contains three functions or submodels, one to model network change (network function) and two behavior functions to model change in ICA and public regard, respectively. These submodels are estimated simultaneously to allow for changes in one (e.g., network change) to inform changes in the other (e.g., behavior change). Thus, as the network changes, sources of peer influence on ICA change, and conversely, as attitudes change, the network 
may change in response. An advantage of the SAOM is that it tests hypothesized friend selection mechanisms and peer influence net of one another (Veenstra \& Steglich, 2012).

Our analysis sought to test several hypotheses regarding selection and influence on ICA. We begin by examining the effect of ICA on friend selection using the network function. In this model, the dyad is the unit of analysis and the outcome is presence or absence of a friendship. Effects pertain to the ICA of the person nominating a friend (ego) and the attitudes of the potential friendship nominee (alter). We include five direct effects related to ICA on friend selection: a linear and square root transformation of ego's ICA (these combine to allow for a nonlinear effect); a linear and square root transformation of alter's ICA; and the cross-product of ego's and alter's ICA. The ego effects capture how ICA affect one's tendency to nominate friends; the alter effects capture how those attitudes affect one's tendency to be named as a friend; and, the cross-product assesses homophily net of these tendencies. In combination these effects test our first hypothesis, that adolescents select friends with similar ICA. We include a similar set of effects to control for effects of public regard on friendship.

The SAOM also controls for several normative friend selection processes, which improves estimates of the effects of individual attributes (e.g., ICA) on friend selection. These structural controls include effects for inertia in the distributions of incoming and outgoing nominations (indegree-popularity and outdegree-activity, respectively, with square root transformations), the tendency to name friends who have nominated oneself (reciprocity), and two forms of triadic effects. The first is a positive indicator of triad closure, or the tendency to name one's friends' friends as one's own friends (geometrically weighted edgewise shared partners, or GWESP). The second is a negative indicator of triad closure in the form of avoiding friendships to peers whose friends are not one's own (Distance-2). The final structural term is an interaction between $\mathrm{re}^{-}$ ciprocity and GWESP.

The network function specified several additional controls. We included a control for whether each pair of students was in the same homeroom class in Year 2, measured at Time 2 (same homeroom). We also included ego, alter, and same effects for sex $($ male $=1)$. To measure homophilous selection on race/ethnicity we created a categorical measure and used the same effect to represent whether the students in each dyad fell in the exact same category. As a follow-up, we also used the dummy variables and included a separate same effect for each dummy variable (leaving dissimilar dyads as the reference group). We created an interaction effect between the same race/ethnicity effect(s) and ego's ICA to test our third hypothesis, about attitudes moderating race/ethnic homophily.

The behavior functions for ICA and public regard include a common set of controls for their distributions (linear and quadratic terms) and effects of individual attributes (effFrom). These include gender, race/ethnicity dummy variables, and mother's immigration status. In addition, we control for the effects of public regard and ICA on one another. We specify peer influence, and test our second hypothesis, using the average similarity effect. This effect captures whether students tend to adopt levels of the respective behavior that either bring them or keep them close to the average of their nominated friends.

We used standard SAOM imputation techniques to treat missing data (Huisman \& Steglich, 2008), which was largely due to panel nonresponse and restricted to network ties and behaviors. The data for the three cohorts were combined using the multigroup option within RSiena (Ripley, Snijders, Boda, Vörös, \& Preciado, 2017). This approach models change over time separately for each of the three cohorts, and in so doing constrains parameter estimates to be equal for each cohort while prohibiting intergrade friendships. The rates of change in friendships and behaviors were allowed to vary between cohorts and over time (via rate effects for each). Convergence for each model was acceptable as indicated by maximum convergence statistics of .15 or less. We achieved sufficient goodness-of-fit as indicated by the estimated models' ability to reproduce the distributions of several relevant summary statistics from the observed networks (see Appendix S1).

\section{Results}

Means and standard deviations by group and wave are provided in Table 1 . On average, students reported fairly positive ICA at each time point. Table 2 reports network structure and change across study waves. Students reported over five friendships on average, with means ranging from 4.5 to 5.8 across grades and waves. The friendship networks exhibited suitable levels of stability from wave to wave, with Jaccard indices ranging from 0.26 to 0.37 . 
Table 1

Means and Standard Deviations for Intergroup Contact Attitudes by Ethnic-Racial Group

\begin{tabular}{lccc}
\hline & Time 1 & Time 2 & Time 3 \\
\hline AAPI & $3.93(.59)$ & $4.10(.64)$ & $4.33(.63)$ \\
Black & $3.96(.69)$ & $3.93(.79)$ & $4.14(.72)$ \\
Latino & $3.89(.84)$ & $3.93(.65)$ & $4.12(.63)$ \\
White & $3.95(.71)$ & $3.96(.70)$ & $4.23(.65)$ \\
Other/native Am & $3.97(.61)$ & $3.97(.62)$ & $3.72(.82)$ \\
Multiracial & $3.99(.63)$ & $4.08(.64)$ & $4.35(.60)$ \\
Overall & $3.95(.70)$ & $3.97(.70)$ & $4.18(.68)$ \\
\hline
\end{tabular}

Note. $\mathrm{AAPI}=$ Asian American and Pacific Islander; Am $=$ American.

Table 2

Network Statistics by Cohort and Wave

\begin{tabular}{lccc}
\hline & Fifth grade & Sixth grade & Seventh grade \\
\hline$N$ & 152 & 191 & 181 \\
Wave 1 & - & 170 & 167 \\
Wave 2 & 151 & 183 & 164 \\
Wave 3 & 147 & 175 & 161 \\
Change & & & \\
Left Wave 1-2 & - & 7 & 16 \\
Left Wave 2-3 & 5 & 9 & 10 \\
Joined 1-2 & 151 & 20 & 13 \\
Joined 2-3 & 1 & 1 & 7 \\
Average degree & & 4.60 & \\
Wave 1 & - & 4.91 & 5.46 \\
Wave 2 & 4.50 & 5.13 & 5.80 \\
Wave 3 & 5.07 & & 5.08 \\
Jaccard & & 0.262 & 0.295 \\
Wave 1-2 & - & 0.316 & 0.374 \\
Wave 2-3 & 0.276 &
\end{tabular}

\section{Network Selection Controls}

Table 3 presents results from the SAOM. We first discuss the network function, which modeled change in the friendship network over time. To provide intuition to the model we begin with controls and emphasize that effects are interpreted as their impact on creating or maintaining a friendship over time. The results for endogenous network structure are typical of SAOM models of friendship dynamics: friendships were unlikely outside of modeled selection processes (negative outdegree); adolescents nominated peers who nominated them (positive reciprocity); adolescents named friends who were friends of their current friends (positive GWESP); the effects of reciprocity and GWESP were not additive (negative reciprocity by GWESP); adolescents avoided ties to peers they did not share friends with (negative Distance 2); adolescents were more likely to name friends whom other students also named as friends (positive indegree-popularity); and adolescents who named many friends were less likely to name additional friends (negative outdegree activity). The model also showed that adolescents in the same homeroom were more likely to be friends. Post hoc tests revealed great variability in such selection across grades, thus we freed this effect to vary accordingly (rows 24-27). Males were somewhat less likely to name friends than females; however, both males and females were more likely to name friends of the same gender. Lastly, the rate effects are of little substantive interest as they index the number of opportunities for change between observations (this is also true for the behavior functions).

\section{Effects of Intergroup Attitudes on Friend Selection}

We now move to our test of how ICA affect friendship, including whether similarity drives friendship. Results for ICA and friend selection appear in rows 13-17 of Table 3. The positive coefficient for the alter effect suggests that youth with more positive ICA are more likely than youth with less positive ICA to be selected as a friend. The significant alter squared term is indicative of a nonlinear selection process - the effect of ICA on being selected as a friend tapers off at more extreme levels. The positive ICA ego effect suggests youth with more positive ICA are more likely to name friends than youth with less positive ICA. There is no evidence that this effect is nonlinear. The nonsignificant Ego $\times$ Alter coefficient reveals no evidence of a tendency toward homophily on ICA net of the other effects in the model. Thus, we find no support for the hypothesis that adolescents prefer friends with similar levels of ICA. This does not mean that adolescents do not select similar friends -as we will describe in more detail next-just that similarity is not the basis for selection (cf. Schaefer et al., 2018).

To more fully understand the joint impact of ego and alter ICA on friend selection we calculated the predicted contribution to the friend selection function across the full range of ego and alter values for such attitudes (Figure 1). Considering the joint values of ego and alter is important, as the model indicates that both ego's and alter's ICA mattered for network structure. Figure 1 shows that friendships are least likely when ego and alter both hold less positive ICA, and most likely when ego and alter 
Table 3

SAOM Estimates for Model Constraining Same Race/Ethnic Effects to be Equal for Each Race/Ethnic Group

\begin{tabular}{|c|c|c|c|}
\hline & & $b$ & $S E$ \\
\hline \multicolumn{4}{|c|}{ Network (friendship) function } \\
\hline 1 & Rate, Cohort $1 \mathrm{~T} 1-\mathrm{T} 2$ & 13.655 & $0.866^{* * *}$ \\
\hline 2 & Rate, Cohort $1 \mathrm{~T} 2-\mathrm{T} 3$ & 12.211 & $0.868^{* * *}$ \\
\hline 3 & Rate, Cohort $2 \mathrm{~T} 1-\mathrm{T} 2$ & 12.289 & $0.848^{* * *}$ \\
\hline 4 & Rate, Cohort $2 \mathrm{~T} 2-\mathrm{T} 3$ & 15.078 & $0.941^{* * *}$ \\
\hline 5 & Rate, Cohort $3 \mathrm{~T} 2-\mathrm{T} 3$ & 17.259 & $1.444^{* * *}$ \\
\hline 6 & Outdegree & -1.949 & $0.139 * * *$ \\
\hline 7 & Indegree-popularity (sqrt) & 0.090 & $0.047^{\dagger}$ \\
\hline 8 & Outdegree-activity (sqrt) & -0.250 & $0.026^{* * *}$ \\
\hline 9 & Reciprocity & 2.317 & $0.097^{* * *}$ \\
\hline 10 & Transitivity (GWESP) & 1.301 & $0.070^{* * *}$ \\
\hline 11 & Reciprocity $\times$ Transitivity & -0.944 & $0.102^{* * *}$ \\
\hline 12 & Number of actors at Distance 2 & -0.142 & $0.019^{* * *}$ \\
\hline 13 & Intergroup contact attitude alter & 0.082 & $0.045^{\dagger}$ \\
\hline 14 & $\begin{array}{l}\text { Intergroup contact } \\
\text { attitude alter squared }\end{array}$ & -0.142 & $0.065^{*}$ \\
\hline 15 & Intergroup contact attitude ego & 0.181 & $0.064^{* *}$ \\
\hline 16 & $\begin{array}{l}\text { Intergroup contact } \\
\text { attitude ego squared }\end{array}$ & -0.055 & 0.075 \\
\hline 17 & $\begin{array}{l}\text { Intergroup Contact } \\
\text { Attitude Ego } \times \text { Alter }\end{array}$ & -0.085 & 0.080 \\
\hline 18 & Public regard alter & 0.017 & 0.032 \\
\hline 19 & Public regard alter squared & 0.038 & 0.037 \\
\hline 20 & Public regard ego & -0.021 & 0.048 \\
\hline 21 & Public regard ego squared & 0.077 & 0.049 \\
\hline 22 & Public Regard Ego $\times$ Alter & 0.058 & 0.051 \\
\hline 23 & Same homeroom & 0.638 & $0.037^{* * *}$ \\
\hline 24 & Same Homeroom $\times$ Cohort $1 \mathrm{~T} 1-\mathrm{T} 2$ & 0.472 & $0.099^{* * *}$ \\
\hline 25 & Same Homeroom $\times$ Cohort $1 \mathrm{~T} 2-\mathrm{T} 3$ & -0.443 & $0.110^{* * *}$ \\
\hline 26 & Same Homeroom $\times$ Cohort $2 \mathrm{~T} 1-\mathrm{T} 2$ & 0.367 & $0.101^{* * *}$ \\
\hline 27 & Same Homeroom $\times$ Cohort $2 \mathrm{~T} 2-\mathrm{T} 3$ & 0.155 & $0.092^{\dagger}$ \\
\hline 28 & Male alter & -0.018 & 0.036 \\
\hline 29 & Male ego & -0.088 & $0.041^{*}$ \\
\hline 30 & Male same & 0.265 & $0.032^{* * *}$ \\
\hline 31 & Race/ethnicity same & 0.257 & $0.033^{* * *}$ \\
\hline 32 & $\begin{array}{l}\text { Public Regard Ego } \times \text { Race } / \\
\text { Ethnicity Same }\end{array}$ & -0.015 & 0.069 \\
\hline 33 & $\begin{array}{l}\text { Intergroup Contact Attitude } \\
\text { Ego } \times \text { Race/Ethnicity Same }\end{array}$ & -0.216 & $0.088^{*}$ \\
\hline \multicolumn{4}{|c|}{ Intergroup contact attitude function } \\
\hline 34 & Rate, Cohort $1 \mathrm{~T} 1-\mathrm{T} 2$ & 1.033 & $0.225^{* * *}$ \\
\hline 35 & Rate, Cohort $1 \mathrm{~T} 2-\mathrm{T} 3$ & 1.214 & $0.285^{* * *}$ \\
\hline 36 & Rate, Cohort $2 \mathrm{~T} 1-\mathrm{T} 2$ & 1.674 & $0.355^{* * *}$ \\
\hline 37 & Rate, Cohort $2 \mathrm{~T} 2-\mathrm{T} 3$ & 0.980 & $0.188^{* * *}$ \\
\hline 38 & Rate, Cohort $3 \mathrm{~T} 2-\mathrm{T} 3$ & 1.636 & $0.333^{* * *}$ \\
\hline 39 & Linear shape & 0.349 & $0.087^{* * *}$ \\
\hline 40 & Quadratic shape & -0.174 & 0.219 \\
\hline 41 & Average similarity & 3.833 & $2.023^{\dagger}$ \\
\hline 42 & Public regard & 0.206 & 0.176 \\
\hline 43 & Male & -0.096 & 0.178 \\
\hline 44 & Asian & 0.258 & 0.364 \\
\hline 45 & Black & -0.226 & 0.222 \\
\hline
\end{tabular}

Table 3

Continued

\begin{tabular}{clrl}
\hline & & $b$ & \multicolumn{1}{c}{$S E$} \\
\hline 46 & Latino & -0.098 & 0.283 \\
47 & Other race/ethnicity & -0.667 & $0.362^{\dagger}$ \\
48 & Multiracial & -0.312 & 0.290 \\
49 & Mother's immigration status & -0.385 & $0.215^{\dagger}$ \\
Public & & \\
50 & Rate, Cohort 1 T1-T2 & 1.871 & $0.384^{* * *}$ \\
51 & Rate, Cohort 1 T2-T3 & 2.234 & $0.563^{* * *}$ \\
52 & Rate, Cohort 2 T1-T2 & 2.764 & $0.566^{* * *}$ \\
53 & Rate, Cohort 2 T2-T3 & 1.723 & $0.309^{* * *}$ \\
54 & Rate, Cohort 3 T2-T3 & 1.877 & $0.369^{* * *}$ \\
55 & Linear shape & 0.002 & 0.057 \\
56 & Quadratic shape & -0.224 & $0.125^{\dagger}$ \\
57 & Average similarity & 3.880 & $1.539^{*}$ \\
58 & Intergroup contact attitude & 0.575 & $0.163^{* * *}$ \\
59 & Male & 0.425 & $0.134^{* *}$ \\
60 & Asian & 0.225 & 0.261 \\
61 & Black & -0.121 & 0.157 \\
62 & Latino & -0.265 & 0.213 \\
63 & Other race/ethnicity & -0.368 & 0.277 \\
64 & Multiracial & 0.137 & 0.205 \\
65 & Mother's immigration status & 0.359 & $0.163^{*}$ \\
\hline
\end{tabular}

Note. Maximum convergence ratio $=0.220$. $\mathrm{SAOM}=$ stochastic actor-oriented model; GWESP $=$ geometrically weighted edgewise shared partners.

${ }^{\dagger} p<.10 .{ }^{*} p<.05 .{ }^{* *} p<.01 . * * * p<.001$.

hold more positive attitudes, all else being equal. In other words, the effect of ICA is to bring peers with similarly high levels together into friendship with a greater likelihood than peers with lower levels. Importantly, this is not attributable to a preference for homophily. Instead, higher ICA youth are both more attractive as friends and more sociable in terms of their nominations.

We tested the same set of five selection effects for public regard and found none to be significant. These are shown in rows 18-22 of Table 3. Thus, public regard has no discernable effect on friend selection dynamics.

\section{Effects of Intergroup Attitudes on Ethnic/Racial Homophily}

We now turn to the question of whether ICA and public regard moderate race/ethnic homophily. In particular, we hypothesized that adolescents with more positive ICA and public regard would be less likely to prefer same race/ethnicity friends (or more open to friends of a different race/ethnicity). Our model reveals, first of all, that race/ethnic 


\section{Contribution to Network Function}

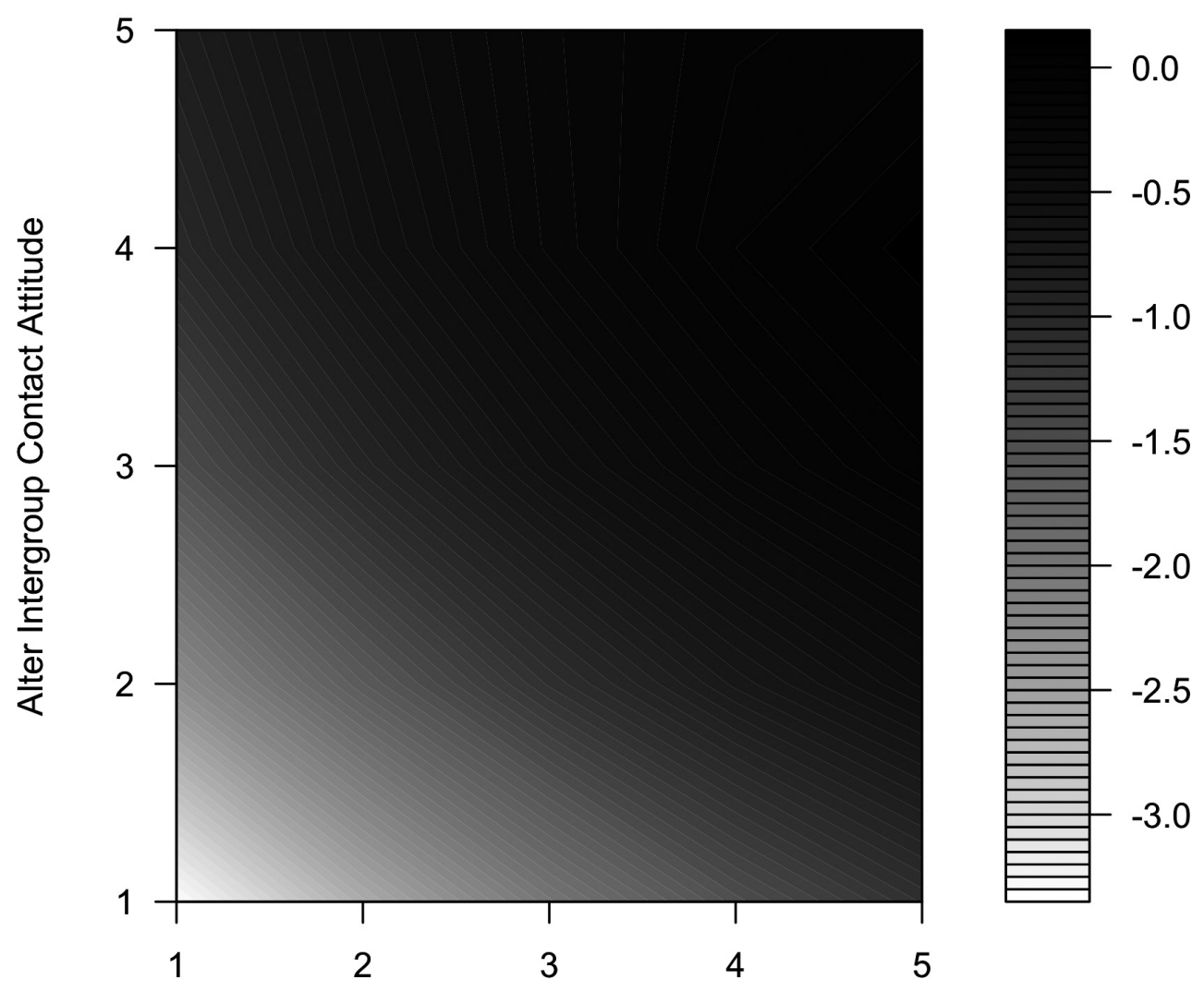

\section{Ego Intergroup Contact Attitude}

Figure 1. Predicted contribution to network function based on joint intergroup contact attitudes (i.e., other group orientation [OGO]) of ego (nominator) and alter (nominee). Values represent the total contribution of OGO selection effects to the network function, irrespective of other model effects. Higher (darker) values indicate a greater likelihood of a friendship occurring. Specifically, given a dyad with a predicted contribution one unit higher than another, the odds of the first dyad exhibiting a friendship are 2.7 (exp[1]) times greater than the second, all else being equal.

selection homophily is present (row 31). Adolescents were $29 \%$ (exp[.257]) more likely to nominate a friend of the same race/ethnicity than someone of a different race/ethnicity, all else being equal. To offer perspective, we turn to Moody, 2001 study of racial friendship segregation across 130 schools in the Add Health data. Moody found that more heterogeneous schools had higher levels of race homophily, though tapering off for the most diverse schools. Using equivalent measures as Moody, our observed school had an overall IQV of .76. Moody reports 18 Add Health schools with a heterogeneity index from .7 to .8 (all other schools were less heterogeneous). In those 18 schools, adolescents were approximately $82 \%$ more likely on average to nominate a same race versus a cross-race friend, net of other selection factors. In comparison, our main effect of $29 \%$ is relatively low, lower than any of the 18 Add Health schools.

We test for moderation of the race homophily effect by creating an interaction between the same race/ethnicity effect and effects for ego ICA and public regard, respectively. The interaction with ICA was negative and significant (row 33). This effect offers evidence that youth with more positive ICA evinced a weaker preference for same race/ ethnic friends than youth with less positive attitudes. To interpret this, we calculated the predicted contribution to the network function based on ego ICA for same and cross-race/ethnic friendships (Figure 2). The plot shows that for adolescents with less positive ICA, the preference for same race friends is stronger than for cross-race friends. At the lowest level, the predicted odds of a same race 


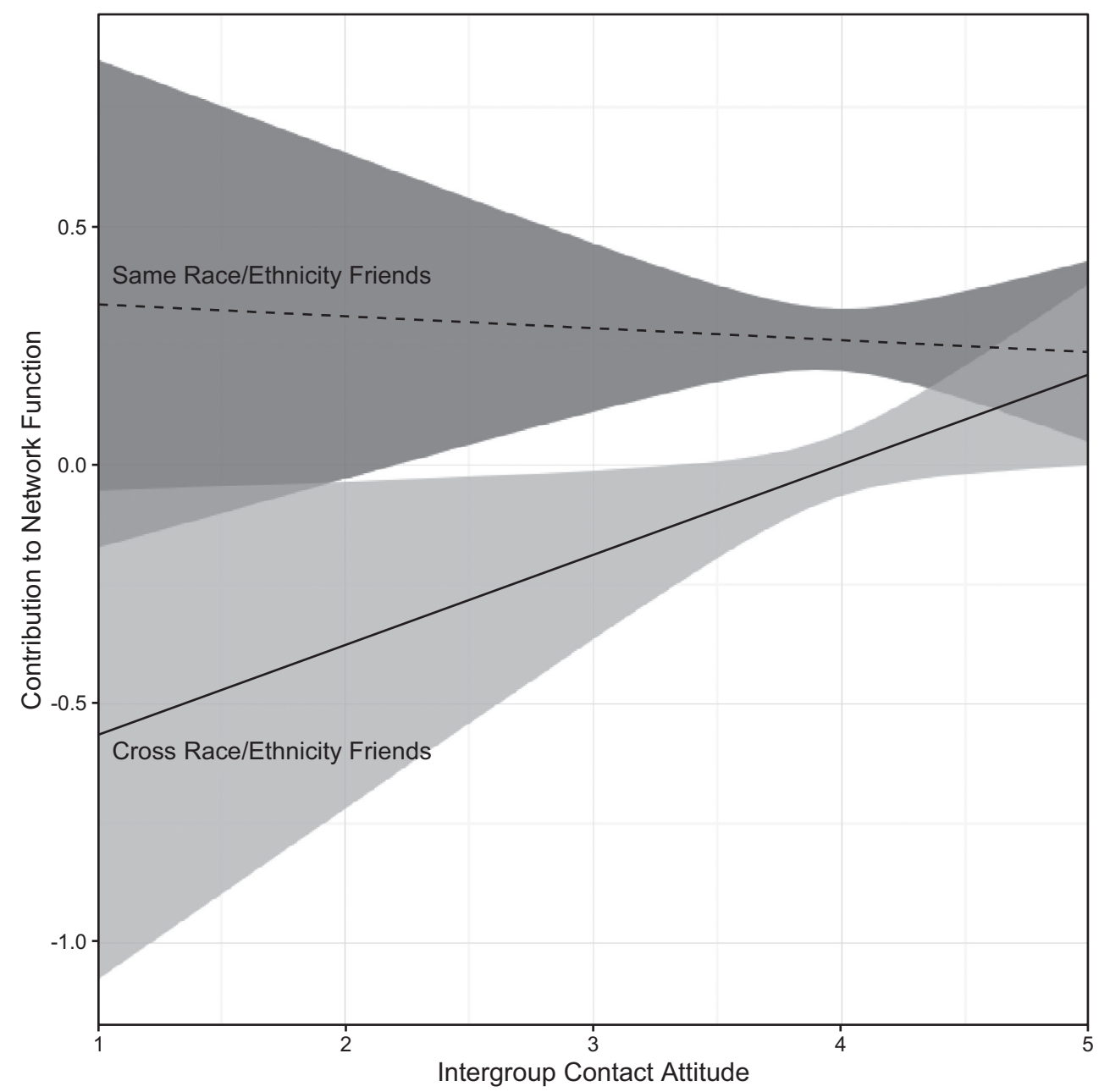

Figure 2. Predicted contribution to network function based on ego intergroup contact attitudes (i.e., other group orientation) for same versus cross-race/ethnic friendships. Shaded areas represent $95 \%$ confidence intervals.

friendship are $250 \%$ greater than the odds of a cross-race friendship. This difference narrows as ego ICA increases. Ultimately, adolescents with the most positive ICA were largely indifferent between choosing friends of the same or a different race/ ethnicity (predicted odds differ by $<5 \%$ ). Significant differences were only observed in the midrange of ICA (note that only $1.3 \%$ of students had ICA in the 1-2 range, where differences were nonsignificant).

\section{Effects of Intergroup Attitudes on Race/Ethnic Homophily by Group}

We further investigated the moderating effect of ICA with a model that separated the race/ethnic homophily effect by group (Table 4). We included six effects to represent homophilous selection for each group. We also included ego and alter effects for each race/ethnic group, though due to the large number of such effects we used score tests to prospectively test whether the inclusion of each effect would impact model fit. Four of these effects had significant score tests and were incorporated. To begin, we observe that Latino/a students were more likely to be named as friends than students from other groups (Table 4, row 37), while there was a borderline tendency for White students to be named less often (row 39). Turning to homophily we find that the effects of same race/ethnicity on friendship were significant for Black, Latino/a, and White youth (Table 4, rows 32-34). Thus, youth from each group were more likely to form or maintain friendships with same race/ethnic peers relative to youth who were dissimilar. Our test for moderation reveals that the strongest effects were observed for Black and Latino/a youth (Table 4, rows 48-49), with nonsignificant effects for Asian, 
White, Multiracial, and Other students. By comparison, public regard did not moderate the effect of race homophily on friendship for either the combined (Table 3, row 32) or disaggregated race/ethnic effect (Table 4, rows 41-46). Thus, Black and Latino/a youth with more positive ICA were less likely than youth in other groups to select same race/ethnicity friends.

\section{Intergroup Attitudes as a Mediator}

We had speculated that homophily in ICA might explain any appearance of public regard homophily (i.e., the effect of public regard homophily on friendship is mediated by homophily in intergroup attitudes). The lack of either intergroup contact or public regard homophily casts doubt on this possibility. However, such null effects could arise if the two attitudes were too highly correlated. Thus, to investigate further we estimated a reduced version of the model reported in Table 3 that excluded the intergroup attitude effects from the network function. Our expectation was premised on the presence of public regard homophily in this model specification. However, public regard did not have a significant effect on friendship in the reduced model, thus it is not possible for homophily in ICA to account for this effect.

\section{Change in Intergroup Attitudes}

We now turn to the behavior functions in Table 3 that predict change in ICA and public regard over time. We begin with the function for ICA (rows 34-49). The positive linear effect combined with a nonsignificant quadratic term indicates that adolescents tended to move toward or remain at higher levels of ICA over time. The negative effects of other race/ethnicity and immigrant mother suggest adolescents with these characteristics had trends toward lower attitudes on average. We found no evidence that public regard affects change in ICA.

Moving to public regard (rows 50-65), the nonsignificant linear term combined with a negative quadratic term reflect a unimodal distribution with students drawn toward the values of 3 and 4 over time. The positive effects for male and immigrant mother suggests that such students tended to have more positive public regard over time. Lastly, we found that ICA predicted change in public regard. In particular, adolescents with more positive ICA were more likely to increase or remain at higher levels of public regard.
Of greatest interest was whether youth influence one another's ICA. The behavior functions tested for peer influence on ICA and public regard. For both, we find significant effects of friends' attitudes on one's own behavior (Table 3, effects 41 and 57, respectively). These effects indicate that adolescents whose friends have higher levels of ICA or public regard will themselves tend to either adopt higher levels or remain at higher levels, relative to adolescents whose friends have lower levels of the respective behavior. We sought to extend these analyses by testing how influence differs for increasing versus decreasing levels of the behavior (e.g., Haas \& Schaefer, 2014), however, we do not have sufficient power to detect such effects (i.e., models with such a specification did not converge).

\section{Discussion}

Given the implications of having a diverse friendship or contact network for developmental outcomes and intergroup relations, more generally, investigation of peer-related processes that make youth "contact ready" is vital (Turner \& Cameron, 2016). Using a novel approach to the study of intergroup dynamics among youth, this study is a first step toward understanding how youth construct, and potentially mutually reinforce, norms around intergroup contact in an ethnically and racially heterogeneous setting. Our analysis produced several key findings, which are buttressed by the use of an implicit measure to study intergroup attitudes within a peer network (system). This enables us to overcome the limitations of previous studies that have relied on measures of perceived peer norms. First, adolescents chose friends based upon their joint values of ICA. Second, we observed that ICA moderated the strength of friend selection based on same race/ethnicity. In addition, we found that students' ICA and their sense of public regard (how others view their ethnic/racial group) were related over time. Finally, we found evidence of peer influence on ICA. These results point to a system where adolescents prefer to befriend more open-minded peers and, in turn, influence one another on intergroup relations. Taken together, they suggest the presence of school-level norms to promote positive intergroup attitudes and that such attitudes may be "contagious."

In this school, adolescents with more positive ICA were more popular. Specifically, these students were more likely to be involved in friendships overall, and their friendships were most likely to be 
Table 4

SAOM Estimates for Model Distinguishing Race/Ethnic Effects by Group

\begin{tabular}{|c|c|c|c|}
\hline & & $b$ & $S E$ \\
\hline \multicolumn{4}{|c|}{ Network (friendship) function } \\
\hline 1 & Rate, Cohort $1 \mathrm{~T} 1-\mathrm{T} 2$ & 13.602 & $0.790^{* * *}$ \\
\hline 2 & Rate, Cohort $1 \mathrm{~T} 2-\mathrm{T} 3$ & 12.179 & $0.895^{* * *}$ \\
\hline 3 & Rate, Cohort $2 \mathrm{~T} 1-\mathrm{T} 2$ & 12.313 & $0.862^{* * *}$ \\
\hline 4 & Rate, Cohort $2 \mathrm{~T} 2-\mathrm{T} 3$ & 15.101 & $1.081^{* * *}$ \\
\hline 5 & Rate, Cohort 3 T2-T3 & 17.003 & $1.388^{* * *}$ \\
\hline 6 & Outdegree & -2.392 & $0.155^{* * *}$ \\
\hline 7 & Indegree-popularity (sqrt) & 0.095 & $0.047^{*}$ \\
\hline 8 & Outdegree-activity (sqrt) & -0.248 & $0.028^{* * *}$ \\
\hline 9 & Reciprocity & 2.312 & $0.093^{* * *}$ \\
\hline 10 & Transitivity (GWESP) & 1.302 & $0.069^{* * *}$ \\
\hline 11 & Reciprocity $\times$ Transitivity & -0.933 & $0.104^{* * *}$ \\
\hline 12 & Number of actors at distance 2 & -0.143 & $0.020^{* * *}$ \\
\hline 13 & Intergroup contact attitude alter & 0.083 & $0.043^{\dagger}$ \\
\hline 14 & $\begin{array}{l}\text { Intergroup contact attitude } \\
\text { alter squared }\end{array}$ & -0.131 & $0.058^{*}$ \\
\hline 15 & Intergroup contact attitude ego & 0.572 & $0.247^{*}$ \\
\hline 16 & Intergroup contact attitude ego squared & -0.047 & 0.073 \\
\hline 17 & $\begin{array}{l}\text { Intergroup Contact } \\
\text { Attitude Ego } \times \text { Alter }\end{array}$ & -0.091 & 0.082 \\
\hline 18 & Public regard alter & 0.023 & 0.032 \\
\hline 19 & Public regard alter squared & 0.036 & 0.039 \\
\hline 20 & Public regard ego & -0.060 & 0.185 \\
\hline 21 & Public regard ego squared & 0.072 & 0.049 \\
\hline 22 & Public Regard Ego $\times$ Alter & 0.053 & 0.053 \\
\hline 23 & Same homeroom & 0.640 & $0.035^{* * *}$ \\
\hline 24 & Same Homeroom $\times$ Cohort $1 \mathrm{~T} 1-\mathrm{T} 2$ & 0.474 & $0.099^{* * *}$ \\
\hline 25 & Same Homeroom $\times$ Cohort $1 \mathrm{~T} 2-\mathrm{T} 3$ & -0.441 & $0.106^{* * *}$ \\
\hline 26 & Same Homeroom $\times$ Cohort $2 \mathrm{~T} 1-\mathrm{T} 2$ & 0.377 & $0.102^{* * *}$ \\
\hline 27 & Same Homeroom $\times$ Cohort $2 \mathrm{~T} 2-\mathrm{T} 3$ & 0.164 & $0.093^{\dagger}$ \\
\hline 28 & Male alter & -0.015 & 0.036 \\
\hline 29 & Male ego & -0.088 & $0.043^{*}$ \\
\hline 30 & Male same & 0.255 & $0.031^{* * *}$ \\
\hline 31 & Asian same & 0.031 & 0.051 \\
\hline 32 & Black same & 0.187 & $0.035^{* * *}$ \\
\hline 33 & Latino/a same & 0.248 & $0.052^{* * *}$ \\
\hline 34 & White same & 0.089 & $0.036^{*}$ \\
\hline 35 & Other race/ethnicity same & 0.046 & 0.056 \\
\hline 36 & Multiracial same & 0.078 & $0.044^{\dagger}$ \\
\hline 37 & Latino/a alter & 0.110 & $0.054^{*}$ \\
\hline 38 & Latino/a ego & 0.047 & 0.062 \\
\hline 39 & White alter & -0.073 & $0.038^{\dagger}$ \\
\hline 40 & White ego & -0.062 & 0.042 \\
\hline 41 & Public Regard Ego $\times$ Asian Same & -0.026 & 0.107 \\
\hline 42 & Public Regard Ego $\times$ Black Same & 0.089 & 0.070 \\
\hline 43 & Public Regard Ego $\times$ Latino/a Same & 0.049 & 0.092 \\
\hline 44 & Public Regard Ego $\times$ White Same & 0.021 & 0.071 \\
\hline 45 & $\begin{array}{l}\text { Public Regard Ego } \times \text { Other } \\
\text { Race/Ethnicity Same }\end{array}$ & -0.053 & 0.118 \\
\hline 46 & Public Regard Ego $\times$ Multiracial Same & -0.007 & 0.083 \\
\hline 47 & $\begin{array}{l}\text { Intergroup Contact Attitude } \\
\text { Ego } \times \text { Asian Same }\end{array}$ & -0.090 & 0.140 \\
\hline
\end{tabular}

Table 4

Continued

\begin{tabular}{|c|c|c|c|}
\hline & & $b$ & $S E$ \\
\hline 48 & $\begin{array}{l}\text { Intergroup Contact Attitude } \\
\text { Ego } \times \text { Black Same }\end{array}$ & -0.204 & $0.092^{*}$ \\
\hline 49 & $\begin{array}{l}\text { Intergroup Contact Attitude } \\
\text { Ego } \times \text { Latino/a Same }\end{array}$ & -0.205 & $0.118^{\dagger}$ \\
\hline 50 & $\begin{array}{l}\text { Intergroup Contact Attitude } \\
\text { Ego } \times \text { White Same }\end{array}$ & -0.128 & 0.096 \\
\hline 51 & $\begin{array}{l}\text { Intergroup Contact Attitude } \\
\text { Ego } \times \text { Other Race/Ethnicity Same }\end{array}$ & 0.081 & 0.157 \\
\hline 52 & $\begin{array}{l}\text { Intergroup Contact Attitude } \\
\text { Ego } \times \text { Multiracial Same }\end{array}$ & -0.090 & 0.111 \\
\hline \multicolumn{4}{|c|}{ Intergroup contact attitude function } \\
\hline 53 & Rate, Cohort $1 \mathrm{~T} 1-\mathrm{T} 2$ & 1.036 & $0.224^{* * *}$ \\
\hline 54 & Rate, Cohort $1 \mathrm{~T} 2-\mathrm{T} 3$ & 1.219 & $0.311^{* * *}$ \\
\hline 55 & Rate, Cohort 2 T1-T2 & 1.670 & $0.343^{* * *}$ \\
\hline 56 & Rate, Cohort $2 \mathrm{~T} 2-\mathrm{T} 3$ & 0.978 & $0.192^{* * *}$ \\
\hline 57 & Rate, Cohort 3 T2-T3 & 1.635 & $0.337^{* * *}$ \\
\hline 58 & Linear shape & 0.350 & $0.083^{* * *}$ \\
\hline 59 & Quadratic shape & -0.170 & 0.201 \\
\hline 60 & Average similarity & 3.889 & $1.771^{*}$ \\
\hline 61 & Public regard & 0.203 & 0.176 \\
\hline 62 & Male & -0.092 & 0.178 \\
\hline 63 & Asian & 0.261 & 0.365 \\
\hline 64 & Black & -0.231 & 0.225 \\
\hline 65 & Latino & -0.100 & 0.290 \\
\hline 66 & Other race/ethnicity & -0.675 & $0.385^{\dagger}$ \\
\hline 67 & Multiracial & -0.325 & 0.288 \\
\hline 68 & Mother's immigration status & -0.385 & $0.216^{\dagger}$ \\
\hline \multicolumn{4}{|c|}{ Public regard function } \\
\hline 69 & Rate, Cohort $1 \mathrm{~T} 1-\mathrm{T} 2$ & 1.881 & $0.410^{* * *}$ \\
\hline 70 & Rate, Cohort $1 \mathrm{~T} 2-\mathrm{T} 3$ & 2.242 & $0.574^{* * *}$ \\
\hline 71 & Rate, Cohort 2 T1-T2 & 2.752 & $0.707^{* * *}$ \\
\hline 72 & Rate, Cohort 2 T2-T3 & 1.717 & $0.324^{* * *}$ \\
\hline 73 & Rate, Cohort 3 T2-T3 & 1.882 & $0.421^{* * *}$ \\
\hline 74 & Linear shape & 0.000 & 0.059 \\
\hline 75 & Quadratic shape & -0.226 & $0.124^{\dagger}$ \\
\hline 76 & Average similarity & 3.869 & $1.651^{*}$ \\
\hline 77 & Intergroup contact attitude & 0.579 & $0.175^{* * *}$ \\
\hline 78 & Male & 0.426 & $0.133^{* *}$ \\
\hline 79 & Asian & 0.220 & 0.269 \\
\hline 80 & Black & -0.119 & 0.156 \\
\hline 81 & Latino & -0.261 & 0.210 \\
\hline 82 & Other race/ethnicity & -0.373 & 0.280 \\
\hline 83 & Multiracial & 0.135 & 0.204 \\
\hline 84 & Mother's immigration status & 0.360 & $0.164^{*}$ \\
\hline
\end{tabular}

Note. Maximum convergence ratio $=0.154$. $\mathrm{SAOM}=$ stochastic actor-oriented model; GWESP $=$ geometrically weighted edgewise shared partners.

${ }^{\dagger} p<.10 . * p<.05 . * * p<.01 . * * * p<.001$.

with other youth who had similarly positive intergroup attitudes. In a heterogeneous setting, it is socially adaptive for youth to prefer to befriend peers with similar ICA who may be part of another 
group in order to cross-racial boundaries to make friendships. Related to this point, in this setting, it was indeed the case that students with more positive ICA were less likely to select friends of the same race/ethnicity than those with less positive attitudes; that is, they had more cross-racial friends. Thus, the views reflected by ICA were evidenced within adolescents' friend selection behavior. Future research should directly test potential mediators to better understand adolescents' tendency to prefer friends with similarly positive ICA.

In this study, we considered that homophily in ICA might be confounded with youths' sense of others' regard for their group (public regard). We found that ICA predicted change in public regard over time, but the reverse was not true. Specifically, adolescents with more positive ICA were more likely to increase or remain at higher levels of public regard. It is possible that youth become more capable of gauging public regard (e.g., Quintana, 1998) in part through increased interactions with peers of other ethnic/racial groups, which is more likely in this context when youth have more favorable dispositions toward having such interactions. Moreover, we found evidence of peer influence on ICA while taking into account youths' public regard perceptions. In particular, students' ICA tended to remain or become more like those of their friends over time (influence effect). Although past research has found that peers influence one another's public regard (Santos et al., 2017) and that intergroup contact influences intergroup attitudes over time (Wölfer, Schmid, Hewstone, \& van Zalk, 2016), the results for ICA are new and represent an extremely important finding.

\section{Implications of Understanding Intergroup Relations in Peer (and School) Contexts}

Taken together, the present results provide insight to the role of peer networks for shaping intergroup relations, and offer promise moving forward. Findings point to a social system within a school where adolescents prefer to befriend more open-minded peers and, in turn, adolescents influence one another on ICA. This accords with several previous findings that underscore the important role of peers. First, prior work suggests that adolescents within the same peer group serve as socializing agents to each other promoting within-group similarity in other ethnic-racial beliefs (e.g., RivasDrake et al., 2017) and, more generally, serve as important social reference groups providing prescriptive and descriptive information about social reality (e.g., Turner, 1991). Second, using different methodology, adolescents within the same peer group have been shown to share similar norms regarding intergroup relations and contact, and these peer norms are known to influence adolescents own intergroup attitudes and behaviors (e.g., Aboud, 2005). Adolescents who either have positive direct or extended peer contact (i.e., an ingroup friend who has an outgroup friend) may also have reduced intergroup anxiety, perceptions of outgroup collective threat, and a higher likelihood of including outgroup members in the self, all of which relate to positive intergroup relations (e.g., Turner et al., 2008). Finally, studies have shown that both direct and extended contact promote positive social norms regarding cross-ethnic friendship, which then result in improved outgroup attitudes among majority children (e.g., Cameron, Rutland, \& Brown, 2007; Feddes, Noack, \& Rutland, 2009).

Overall, the results are also consistent with previous research on the attitudes and behavior of early adolescents that finds this developmental stage noteworthy for the influence of peers (e.g., Brown, 1990). Importantly, this peer influence extends the concept of social group norms for cross-race interaction from the macrolevel of race and culture to the micro-level of the school-based social network. Inclusive social norms have long been identified as an important facilitator in intergroup contact reducing prejudice (e.g., Allport, 1954). This study highlights that even when macrolevel (i.e., school) conditions encourage intergroup contact, negative influence at the microlevel (i.e., peers who do not have positive ICA) may work against such norms by reducing adolescents' positive attitudes regarding intergroup contact. Indeed, the normative beliefs of peers may be especially important for adolescents because reference groups are "psychologically and socially meaningful to individuals" (Leach \& Vliek, 2008, p. 541). Peer norms also determine how individual peer members are evaluated. For example, Castelli, De Amicis, and Sherman (2007) discovered that children who paired in cross-ethnic dyads voluntarily were evaluated more negatively by ingroup peers than children who were assigned to be in cross-ethnic dyads by a teacher.

This pattern of results demonstrates the importance of peer-level strategies in efforts to improve intergroup contact and inevitably intergroup relations. With an ethnically and racially hetergenous school setting like the one sampled here, a focus on peer interactions may highlight unique intergroup attitude changes not necessarily captured by 
broader strategies. For example, it is possible for school-based strategies that encourage intergroup contact to be met with public acceptance but not necessarily private acceptance (i.e., normative social influence). Thus, adolescents may adhere and comply with those norms without internalizing them. However, peer-based strategies might influence both private and public acceptance (e.g., informational social influence) leading to internalized social norms regarding intergroup contact. Such strategies have been found to be effective in the past. For instance, Paluck and Shepherd (2012) found that school interventions that target the behaviors of highly socially connected students will subsequently change the attitudes and behaviors of their peers.

\section{Limitations and Future Directions}

Although this study provides novel insights into intergroup relations among youth, there are important caveats that must be considered in drawing conclusions. One that could be addressed in future research is our lack of data on students' residence or individual-level data on their socioeconomic status, which could play a role in homophily observed between students. Two other salient issues regard the school site. It was an ethnically and racially heterogeneous setting, which is becoming less common in the United States and thus limits the generalizability of the present findings. In addition, the school was actively implementing a social-emotional learning program to promote a positive diversity climate among adults and youth in the building. Different results might emerge in heterogeneous schools without such efforts to promote positive social norms or with high levels of conflict, more generally. Yet, this study provides support for the development of future research in which these limitations can be addressed with a multisite design to include schools that vary in terms of heterogeneity and climate around diversity issues.

An additional limitation is that we did not have the power to determine whose influence matters more-whether friends with more positive intergroup attitudes youth "pull" those with less positive attitudes up, or vice versa-but the selection effects offer some clues in this regard. In particular, students with more positive ICA had an elevated friendship likelihood compared to youth with less positive attitudes, suggesting greater social acceptance. Since social acceptance enhances one's influence (Rambaran et al., 2017), it stands to reason that the strongest source of influence was likely youth with more positive attitudes. Assuming that influence is from youth with more to those with less positive intergroup attitudes, then these results suggest that building such attitudes may be a viable means to reduce racial/ethnic friendship segregation. This would occur as friends influence one another to be more open, and those open attitudes translate into more cross-group friendships. Future work in this area should further investigate these mechanisms in larger samples.

\section{Conclusion}

Adolescents' attitudes toward interacting with ethnically diverse peers are of critical importance for their long-term academic and social experiences. This study offers new insights to the power of peer networks for shaping intergroup relations in an ethnically and racially diverse school, where there are ample opportunities for cross-group interaction and friendship. As we have seen, the findings speak to the complex associations between adolescents' own dispositions toward intergroup contact and the social system in which these dispositions may be enacted. By examining attitudes pertinent to ethnicity and race in a sample that reflects a cross-section of ethnic-racial groups, the study also addresses recent calls to attend to issues of equity and justice in developmental science (Killen, Rutland, \& Yip, 2016). Future studies should continue investigations into the interplay of macro and microlevel factors among diverse groups, so that researchers and educators may obtain additional insights into adolescents' social behaviors and attitudes in ethnically and racially diverse contexts.

\section{References}

Aboud, F. E. (2005). The development of prejudice in childhood and adolescence. In J. F. Dovidio, P. S. Glick, \& L. A. Rudman (Eds.), On the nature of prejudice: Fifty years after Allport (pp. 310-326). Malden, MA: Blackwell. https://doi.org/10.1002/9780470773963

Aboud, F. E., Mendelson, M., \& Purdy, K. (2003). Crossrace peer relations and friendship quality. International Journal of Behavioral Development, 27, 165-173. https:// doi.org/10.1080/01650250244000164

Allport, G. W. (1954). The nature of prejudice. Cambridge, MA: Addison-Wesley.

Bagci, S. C., Rutland, A., Kumashiro, M., Smith, P. K., \& Blumberg, H. (2014). Are minority status children's cross-ethnic friendships beneficial in a multiethnic context? British Journal of Developmental Psychology, 32, 107115. https:/ /doi.org/10.1111/bjdp.12028

Brechwald, W. A., \& Prinstein, M. J. (2011). Beyond homophily: A decade of advances in understanding 
peer influence processes. Journal of Research on Adolescence, 21, 166-179. https://doi.org/10.1111/j.1532-7795. 2010.00721.x

Brown, B. B. (1990). Peer groups and peer cultures. In S. S. Feldman \& G. R. Elliot (Eds.), At the threshold: The developing adolescent (pp. 171-196). Cambridge, MA: Harvard University Press.

Brown, B. B., Bakken, J. P., Ameringer, S. W., \& Mahon, S. D. (2008). A comprehensive conceptualization of the peer influence process in adolescence. In M. J. Prinstein \& K. Dodge (Eds.), Understanding peer influence in children and adolescents (pp. 17-44). Cambridge, MA: Harvard.

Brown, B., \& Larson, J. (2009). Peer relationships in adolescence. In R. M. L. Steinberg (Ed.), Handbook of adolescent psychology: Contextual influences on adolescent development (Vol. 2, 3rd ed., pp. 74-103). Hoboken, NJ: Wiley.

Cameron, L., Rutland, A., \& Brown, R. (2007). Promoting children's positive intergroup attitudes towards stigmatized groups: Extended contact and multiple classification skills training. International Journal of Behavioral Development, 31, 454-466. https://doi.org/10.1177/ 0165025407081474

Cameron, L., Rutland, A., Brown, R., \& Douch, R. (2006). Changing children's intergroup attitudes toward refugees: Testing different models of extended contact. Child Development, 77, 1208-1219. https://doi.org/10. 1111/j.1467-8624.2006.00929.x

Carlson, C. I., Wilson, K. D., \& Hargrave, J. L. (2003). The effect of school racial composition on Hispanic intergroup relations. Journal of Social and Personal Relationships, 20, 203-220. https://doi.org/10.1177/026540750 30202005

Castelli, L., De Amicis, L., \& Sherman, S. J. (2007). The loyal member effect: On the preference for ingroup members who engage in exclusive relations with the ingroup. Developmental Psychology, 43, 1347-1359. https: / / doi.org/10.1037/0012-1649.43.6.1347

Crystal, D., Killen, M., \& Ruck, M. (2008). It is who you know that counts: Intergroup contact and judgments about race-based exclusion. British Journal of Developmental Psychology, 26, 51-70. https://doi.org/10.1348/ 026151007X198910

Davies, K., Tropp, L. R., Aron, A., Pettigrew, T. F., \& Wright, S. C. (2011). Cross-group friendships and intergroup attitudes: A meta-analytic review. Personality and Social Psychology Review, 15, 332-351. https://doi.org/ $10.1177 / 1088868311411103$

Dijkstra, J. K., \& Gest, S. D. (2015). Peer norm salience for academic achievement, prosocial behavior, and bullying: Implications for adolescent school experiences. The Journal of Early Adolescence, 35(1), 79-96. https://doi. org $/ 10.1177 / 0272431614524303$

Feddes, A. R., Noack, P., \& Rutland, A. (2009). Direct and extended friendship effects on minority and majority children's interethnic attitudes: A longitudinal study. Child Development, 80, 377-390. https://doi.org/10. $1111 / \mathrm{j} .1467-8624.2009 .01266 . x$
Fletcher, A. C., Rollins, A., \& Nickerson, P. (2004). The extension of school-based inter-and intraracial children's friendships: Influences on psychosocial wellbeing. American Journal of Orthopsychiatry, 74, 272-285. https: / / doi.org/10.1037/0002-9432.74.3.272

Galván, A., Spatzier, A., \& Juvonen, J. (2011). Perceived norms and social values to capture school culture in elementary and middle school. Journal of Applied Developmental Psychology, 32, 346-353. https://doi.org/10. 1016/j.appdev.2011.08.005

Gieling, M., Thijs, J., \& Verkuyten, M. (2014). Dutch adolescents' tolerance of Muslim immigrants: The role of assimilation ideology, intergroup contact, and national identification. Journal of Applied Social Psychology, 44, 155-165. https://doi.org/10.1111/jasp.12220

Graham, S., Munniksma, A., \& Juvonen, J. (2014). Psychosocial benefits of cross-ethnic friendships in urban middle schools. Child Development, 85, 469-483. https: / / doi.org/10.1111/cdev.12159

Gurin, P., Dey, E. L., Hurtado, S., \& Gurin, G. (2002). Diversity and higher education: Theory and impact on educational outcomes. Harvard Educational Review, 72, 330-366. https:/ / doi.org/10.17763/haer.72.3.01151786u134n051

Haas, S. A., \& Schaefer, D. R. (2014). With a little help from my friends? Asymmetrical social influence on adolescent smoking initiation and cessation. Journal of Health and Social Behavior, 55, 126-143. https://doi.org/ $10.1177 / 0022146514532817$

Huisman, M., \& Steglich, C. (2008). Treatment of nonresponse in longitudinal network studies. Social networks, 30(4), 297-308. https://doi.org/10.1016/j.socnet. 2008.04.004

Jagers, R. (2016). Framing social and emotional learning among African American youth: Toward and integritybased approach. Human Development, 59, 1-3. https:// doi.org/10.1159/000447005

Jayakumar, U. M. (2008). Can higher education meet the needs of an increasingly diverse and global society? Campus diversity and cross-cultural workforce competencies. Harvard Educational Review, 78, 615-651. https: / / doi.org/10.17763/haer.78.4.b60031p350276699

Kawabata, Y., \& Crick, N. R. (2008). The role of crossracial/ethnic friendships in social adjustment. Developmental Psychology, 44, 1177-1183. https://doi.org/10. 1037/0012-1649.44.4.1177

Kawabata, Y., \& Crick, N. R. (2011). The significance of cross-racial/ethnic friendships: Associations with peer victimization, peer support, sociometric status, and classroom diversity. Developmental Psychology, 47, 17631775. https://doi.org/10.1037/a0025399

Kawabata, Y., \& Crick, N. R. (2015). Direct and interactive links between cross-ethnic friendships and peer rejection, internalizing symptoms, and academic engagement among ethnically diverse children. Cultural Diversity and Ethnic Minority Psychology, 21, 191-200. https: / / doi.org/10.1037/a0038451

Kiesner, J., Maass, A., Cadinu, M., \& Vallese, I. (2003). Risk factors for ethnic prejudice during early 
adolescence. Social Development, 12, 288-308. https://d oi.org/10.1111/1467-9507.00234

Killen, M., Rutland, A., \& Yip, T. (2016). Equity and justice in developmental science: Discrimination, social exclusion, and intergroup attitudes. Child Development, 87(5), 1317-1336. https:/ / doi.org/10.1111/cdev.12593

Laninga-Wijnen, L., Harakeh, Z., Steglich, C., Dijkstra, J. K., Veenstra, R., \& Vollebergh, W. (2017). The norms of popular peers moderate friendship dynamics of adolescent aggression. Child Development, 88, 1265-1283. https://doi.org/10.1111/cdev.12650

Leach, C. W., \& Vliek, M. W. (2008). Group membership as a "frame of reference" for interpersonal comparison. Social and Personality Psychology Compass, 2, 539-544. https:/ / doi.org/10.1111/j.1751-9004.2007.00058.x

Lease, A. M., \& Blake, J. J. (2005). A comparison of majority-race children with and without a minority-race friend. Social Development, 14, 20-41. https://doi.org/ 10.1111/j.1467-9507.2005.00289.x

Lee, S. J. (1996). Unraveling the "model minority" stereotype: Listening to Asian American youth. New York, NY: Teachers College.

Lerner, R. M., \& Steinberg, L. (2009). Handbook of adolescent psychology: Individual bases of adolescent development. Hoboken, NJ: Wiley. https://doi.org/10.1002/ 9780470479193

McGlothlin, H., \& Killen, M. (2010). How social experience is related to children's intergroup attitudes. European Journal of Social Psychology, 40, 625-634. https:// doi.org/10.1002/ejsp.733

McLeod, J. (1995). Ain't no makin' it: Aspirations and attainment in a low-income neighborhood. Boulder, CO: Westview Press.

McPherson, M., Smith-Lovin, L., \& Cook, J. M. (2001). Birds of a feather: Homophily in social networks. Annual Review of Sociology, 27, 415-444. https://doi. org/10.1146/annurev.soc.27.1.415

Moody, J. (2001). Race, school integration, and friendship segregation in America. American Journal of Sociology, 107, 12-43.

Osgood, D. W., Ragan, D. T., Wallace, L., Gest, S. D., Feinberg, M. E., \& Moody, J. (2013). Peers and the emergence of alcohol use: Influence and selection processes in adolescent friendship networks. Journal of Research on Adolescence, 23, 500-512. https://doi.org/ 10.1111/jora.12059

Paluck, E. L., \& Shepherd, H. (2012). The salience of social referents: A field experiment on collective norms and harassment behavior in a school social network. Journal of Personality and Social Psychology, 103, 899-915. https:/ /doi.org/10.1037/a0030015

Pettigrew, T. F., \& Tropp, L. R. (2008). How does intergroup contact reduce prejudice? Meta-analytic tests of three mediators. European Journal of Social Psychology, 38, 922-934. https://doi.org/10.1002/ejsp.504

Pettigrew, T. F., \& Tropp, L. R. (2012). When groups meet: The dynamics of intergroup contact. New York, NY: Psychology Press.
Phinney, J. S. (1992). The multigroup ethnic identity measure: A new scale for use with diverse groups. Journal of Adolescent Research, 7, 156-176. https://doi.org/10. $1177 / 074355489272003$

Phinney, J. S., Ferguson, D. L., \& Tate, J. D. (1997). Intergroup attitudes among ethnic minority adolescents: A causal model. Child Development, 68, 955-969. https:// doi.org/10.2307/1132044

Pollock, M. (2004). Colormute: Race talk dilemmas in an American school. Princeton, NJ: Princeton University Press.

Quintana, S. M. (1998). Development of children's understanding of ethnicity and race. Applied E Preventive Psychology: Current Scientific Perspectives, 7, 27-45. https:/ / doi.org/10.1016/S0962-1849(98)80020-6

Rambaran, J. A., Hopmeyer, A., Schwartz, D., Steglich, C., Badaly, D., \& Veenstra, R. (2017). Academic functioning and peer influences: A short-term longitudinal study of network- behavior dynamics in middle adolescence. Child Development, 88, 523-543. https://doi. org/10.1111/cdev.12611

Ramiah, A. A., Schmid, K., Hewstone, M., \& Floe, C. (2015). Why are all the White (Asian) kids sitting together in the cafeteria? Resegregation and the role of intergroup attributions and norms. British Journal of Social Psychology, 54, 100-124. https://doi.org/10.1111/ bjso.12064

Reimer, N. K., Becker, J. C., Benz, A., Christ, O., Dhont, K., Klocke, U., . . . Hewstone, M. (2017). Intergroup contact and social change: Implications of negative and positive contact for collective action in advantaged and disadvantaged groups. Personality and Social Psychology Bulletin, 43, 121-136. https://doi.org/10.1177/ 0146167216676478

Ripley, R. M., Snijders, T. A. B., Boda, Z., Vörös, A., \& Preciado, P. (2017). Manual for RSiena. Retrieved from http://www.stats.ox.ac.uk/ snijders/siena/

Rivas-Drake, D., Seaton, E. K., Markstrom, C., Quintana, S., Syed, M., Lee, R. M., . . . Yip, T. (2014). Ethnic and racial identity in adolescence: Implications for psychosocial, academic, and health outcomes. Child Development, 85(1), 40-57. https://doi.org/10.1111/cdev. 12200

Rivas-Drake, D., Umaña-Taylor, A. J., Schaefer, D. R., \& Medina, M. (2017). Ethnic-racial identity and friendships in early adolescence. Child Development, 88, 710724. https:/ /doi.org/10.1111/cdev.12790

Rosenbloom, S. R., \& Way, N. (2004). Experiences of discrimination among African American, Asian American, and Latino adolescents in an urban high school. Youth $\mathcal{E}$ Society, 35, 420-451. https://doi.org/10.1177/ 0044118 X03261479

Ryan, A. M. (2001). The peer group as a context for the development of young adolescent motivation and achievement. Child Development, 72, 1135-1150. https: / / doi.org/10.1111/1467-8624.00338

Saleem, M., Yang, G. L., \& Ramasubramanian, S. (2016). Reliance on direct and mediated contact: Longitudinal effects of sources of information on public policies 
representative of outgroup harm. Journal of Communication, 66, 604-624. https://doi.org/10.1111/jcom.12234

Santos, C., Kornienko, O., \& Rivas-Drake, D. (2017). Peer network influence on ethnic-racial identity development: A multi-site investigation. Child Development, 88, 725-742. https://doi.org/10.1111/cdev.12789

Schaefer, D. R., Kornienko, O., \& Fox, A. M. (2011). Misery does not love company: Network selection mechanisms and depression homophily. American Sociological Review, 76, 764-785. https:/ / doi.org/10.1177/0003122411420813

Schaefer, D. S., Simpkins, S. D., \& Ettekal, A. V. (2018). Can extracurricular activities reduce adolescent race/ ethnic friendship segregation? In D. Alwin, D. Felmlee, \& D. Kreager (Eds.), Social networks and the life course (pp. 315-339). New York, NY: Springer.

Scottham, K. M., Sellers, R. M., \& Nguyên, H. X. (2008). A measure of racial identity in African American adolescents: The development of the Multidimensional Inventory of Black Identity-Teen. Cultural Diversity and Ethnic Minority Psychology, 14, 297-306. https://doi. org/10.1037/1099-9809.14.4.297

Sellers, R. M., Rowley, S. A. J., Chavous, T. M., Shelton, J. N., \& Smith, M. A. (1997). Multidimensional Inventory of Black identity: A preliminary investigation of reliability and constuct validity. Journal of Personality and Social Psychology, 73, 805-815. https://doi.org/10.1037/ 0022-3514.73.4.805

Sellers, R. M., Smith, M. A., Shelton, J. N., Rowley, S. A., \& Chavous, T. M. (1998). Multidimensional model of racial identity: A reconceptualization of African American racial identity. Personality and Social Psychology Review, 2, 18-39. https://doi.org/10.1207/s15327957pspr0201_2

Sijtsema, J. J., Ojanen, T., Veenstra, R., Lindenberg, S., Hawley, P. H., \& Little, T. D. (2010). Forms and functions of aggression adolescent friendship selection and influence: A longitudinal social network analysis. Social Development, 19, 515-534. https://doi.org/10.1111/ j.1467-9507.2009.00566.x

Snijders, T. A., Van de Bunt, G. G., \& Steglich, C. E. (2010). Introduction to stochastic actor-based models for network dynamics. Social Networks, 32(1), 44-60. https://doi.org/10.1016/j.socnet.2009.02.004

Thijs, J., \& Verkuyten, M. (2014). School ethnic diversity and students' interethnic relations. British Journal of Educational Psychology, 84(1), 1-21. https://doi.org/10. 1111/bjep.12032

Tropp, L. R., \& Bianchi, R. A. (2006). Valuing diversity and interest in intergroup contact. Journal of Social Issues, 62, 533-551. https://doi.org/10.1111/j.15404560.2006.00472.x

Tropp, L. R., O’Brien, T. C., Gonzalez, R. G., Valdenegro, D., Migacheva, K., de Tezanos-Pinto, P., . . . Cayul, O. (2016). How school norms, peer norms, and discrimination predict interethnic experiences among ethnic minority and majority youth. Child Development, 87, 1436-1451. https://doi.org/10.1111/cdev.12608

Tropp, L. R., O’Brien, T. C., \& Migacheva, K. (2014). How peer norms of inclusion and exclusion predict children's interest in cross-ethnic friendships. Journal of Social Issues, 70, 151-166. https:/ / doi.org/10.1111/josi.12052

Tropp, L. R., \& Pettigrew, T. F. (2005). Relationships between intergroup contact and prejudice among minority and majority status groups. Psychological Science, 16, 951-957. https: / / doi.org/10.1111/j.1467-9280.2005.01643.x

Turner, J. C. (1991). Social influence. Milton Keynes, UK: Open University Press.

Turner, R. N., \& Cameron, L. (2016). Confidence in contact: A new perspective on promoting cross- group friendship among children and adolescents. Social Issues and Policy Review, 10, 212-246. https:/ / doi.org/10.1111/sipr.12023

Turner, R. N., Hewstone, M., \& Voci, A. (2007). Reducing explicit and implicit outgroup prejudice via direct and extended contact: The mediating role of self-disclosure and intergroup anxiety. Journal of Personality and Social Psychology, 93, 369. https://doi.org/10.1037/0022-3514. 93.3.369

Turner, R. N., Hewstone, M., Voci, A., Paolini, S., \& Christ, O. (2007). Reducing prejudice via direct and extended cross-group friendship. European Review of Social Psychology, 18, 212-255. https://doi.org/10.1080/ 10463280701680297

Turner, R. N., Hewstone, M., Voci, A., \& Vonofakou, C. (2008). A test of the extended intergroup contact hypothesis: The mediating role of intergroup anxiety, perceived ingroup and outgroup norms, and inclusion of the outgroup in the self. Journal of Personality and Social Psychology, 95, 843-860. https://doi.org/10.1037/ a0011434

Umaña-Taylor, A. J., Quintana, S. M., Lee, R. M., Cross, W. E., Rivas-Drake, D., Schwartz, S. J., . . S Seaton, E. (2014). Ethnic and racial identity during adolescence and into young adulthood: An integrated conceptualization. Child Development, 85(1), 21-39. https://doi. org/10.1111/cdev.12196

Valenzuela, A. (1999). Subtractive schooling: U.S.-Mexican youth and the politics of caring. Albany, NY: SUNY.

Veenstra, R., Dijkstra, J. K., Steglich, C., \& Van Zalk, M. H. (2013). Network-behavior dynamics. Journal of Research on Adolescence, 23, 399-412. https://doi.org/ 10.1111/jora.12070

Veenstra, R., \& Steglich, C. (2012). Actor-based model for network and behavior dynamics: A tool to examine selection and influence processes. In B. Laursen, T. D. Little, \& N. A. Card (Eds.), Handbook of developmental research methods (pp. 598-618). New York, NY: Guilford.

Verkuyten, M. (2005). Ethnic group identification and group evaluation among minority and majority groups: Testing the multiculturalism hypothesis. Journal of Personality and Social Psychology, 88, 121-138. https://doi. org/10.1037/0022-3514.88.1.121

Verkuyten, M. (2007). Social psychology and multiculturalism. Social and Personality Psychology Compass, 1, 280297. https: / / doi.org/10.1111/j.1751-9004.2007.00011.x

Weissberg, R. P., Durlak, J. A., Domitrovich, C. E., \& Gullotta, T. P. (2015). Social and emotional learning: Past, present and future. In J. A. Durlak, C. E. Domitrovich, 
R. P. Weissberg, \& T. P. Gullotta (Eds.), Handook of social and emotional learning: Research and practice (pp. 319). New York, NY: Guilford.

Wölfer, R., Schmid, K., Hewstone, M., \& van Zalk, M. (2016). Developmental dynamics of intergroup contact and intergroup attitudes: Long-term effects in adolescence and early adulthood. Child Development, 87, 14661478. https://doi.org/10.1111/cdev.12598

Wright, S. C., Aron, A., McLaughlin-Volpe, T., \& Ropp, S. A. (1997). The extended contact effect: Knowledge of cross-group friendships and prejudice. Journal of
Personality and Social Psychology, 73(1), 73-90. https://d oi.org/10.1037/0022-3514.73.1.73

\section{Supporting Information}

Additional supporting information may be found in the online version of this article at the publisher's website:

Appendix S1. Goodness-of-fit indicators for network analyses 